\title{
EFFECTIVENESS OF RED GINGER IN RELIEVING MENSTRUAL PAIN
}

\author{
Miftakhul Mualimah \\ Diploma Program in Midwivery, Faculty of Health Science, Kadiri University
}

\begin{abstract}
Background: The meta-analysis of six studies found that that Ginger effectively reduces menstrual pain. The two studies that compared Ginger to NSAIDs found that Ginger reduced menstruation pain comparably to NSAIDs. These included mefanamic acid (Ponstan) and ibuprofen (Motrin) both common NSAIDs prescribed for severe menses pain. To the best of the author knowledge there is no studies have been carried out investigating the effectiveness of ginger that is grown in Java in reducing menstrual pain. This study aimed to examine the effectiveness of red ginger in relieving menstrual pain.

Subjects and Method: This was a randomized controlled trial conducted at SMAN 5 high school, Kediri, East Java. A sample of female students with menstrual pain were selected for this study by random sampling. This sample of students were divided into 2 groups by randomization, consisting of 13 students receiving red ginger extract beverage and 13 students receiving mefenamic acid (Ponstan). The dependent variable was intensity of menstrual pain. The independent variable was the provision of ginger extract beverage. Pain intensity was measured by visual analog scale (VAS). Difference in pain score between the 2 gruops was tested by Mann Whitney.

Results: After taking the intervention, the pain score in the red ginger group was slightly higher (mean=2.7; $\mathrm{SD}=1.1$ ) than the mefenamic acid group (mean=2.5; $\mathrm{SD}=1.3)$, but it was statistically insignificant $(\mathrm{p}=0.277)$.

Conclusion: The effectiveness of red ginger extract as a menstrual pain reliever is comparable to mefenamic acid.
\end{abstract}

Keywords: red ginger, mefanamic acid, intensity, menstrual pain

Correspondence: Miftakhul Mualimah. Diploma Program in Midwivery, Faculty of Health Science, Kadiri University, Kediri, East Java. Email: miftahulmualimah@gmail.com. Mobile: +6285235127983. 